\title{
Perceptions of Oncologists, Healthcare Policy Makers, Patients and the General Population on the Value of Pharmaceutical Treatments in Oncology
}

\author{
José A. Sacristán · Luís Lizan · Marta Comellas · Pilar Garrido • \\ Cristina Avendaño $\cdot$ Juan J. Cruz-Hernández $\cdot$ Javier Espinosa \\ Tatiana Dilla
}

Received: August 5, 2016/Published online: October 7, 2016

(c) The Author(s) 2016. This article is published with open access at Springerlink.com

\section{ABSTRACT}

Introduction: The purpose of this study was to explore the main factors explaining the relative weight of the different attributes that determine the value of oncologic treatments from the

Enhanced content To view enhanced content for this article go to http://www.medengine.com/Redeem/ 14E6F0601466A5CC.

J. A. Sacristán $(\bowtie) \cdot$ T. Dilla

Medical Department, Lilly, Madrid, Spain

e-mail: sacristan_jose@lilly.com

L. Lizan · M. Comellas

Outcomes'10, Castellón, Spain

L. Lizan

Department of Medicine, Jaime I University, Castellón, Spain

P. Garrido

Medical Oncology Department, University Hospital

Ramon y Cajal, Madrid, Spain

C. Avendaño

Clinical Pharmacology Department, Puerta de Hierro-Majadahonda Hospital, Madrid, Spain

J. J. Cruz-Hernández

Salamanca Institute for Biomedical Research,

University Hospital Salamanca, Salamanca, Spain

J. Espinosa

Medical Oncology Department, General Hospital

Ciudad Real, Ciudad Real, Spain different perspectives of healthcare policy makers (HCPM), oncologists, patients and the general population in Spain.

Methods: Structured interviews were conducted to assess: (1) the importance of the attributes on treatment choice when comparing a new cancer drug with a standard cancer treatment; (2) the importance of survival, quality of life (QoL), costs and innovation in cancer; and (3) the most worrying side effects related to cancer drugs.

Results: A total of 188 individuals participated in the study. For all participants, when choosing treatments, the best rated characteristics were greater efficacy, greater safety, treatment adaptation to patients' individual requirements and the rapid reincorporation of patients to their daily activities. There were important differences among participants in their opinion about survival, QoL and cost. In general, oncologists, patients, and the general population gave greater value to gains in QoL than healthcare policy makers. Compared to other participants healthcare policy makers gave greater importance to the economic impact related to oncology treatments. 
Conclusions: Gains in QoL, survival, safety, cost and innovation are perceived differently by different groups of stakeholders. It is recommended to consider the perspective of different stakeholders in the assessment of a new cancer drugs to obtain more informed decisions when deciding on the most appropriate treatment to use.

Funding: Eli Lilly \& Co, Madrid (Spain).

Keywords: Clinically meaningful outcomes; Innovation; Oncology; Spain; Value

\section{INTRODUCTION}

Cancer is one of the leading causes of morbidity and mortality worldwide, with 14.1 million new cancer cases and 8.2 million cancer deaths [1]. It is estimated that within two decades, cancer rates will double to approximately 22 million cases [2]. Regardless of this increase in the number of new cancer cases each year, patients' survival has improved due to the drugs that are currently available, together with the progress of cancer prevention and diagnostics [2].

The study and understanding of molecular mechanisms related to cancer has allowed identifying and developing novel target treatments. Some new therapies delay tumor growth, opening up the prospect for patients' long-term survival and turning cancer into a chronic disease [3]. At the same time, expenditure on cancer drugs has grown steadily [4]. It has been argued that the high cost of contemporary cancer drugs may signal even greater costs for future drugs [5]. Consequently, the debates regarding the rise of healthcare costs and the development and value of new medical technologies are increasingly present.
In today's economic context, governments have the challenge to provide high quality and innovative care to meet the population's health needs most effectively while managing health care budgets and safeguarding the basic principles of equity, access and choice. For this reason, to control healthcare costs, governments need to apply evidence-based principles in evaluating the new medicines, often using "additional cost per additional health benefit" to measure "value for money" [6].

Currently, there is intense debate regarding the value considerations of new cancer drugs. The American Society of Clinical Oncology (ASCO) has proposed a conceptual framework to assess the value of cancer treatment options through their clinical benefits (efficacy), toxicity (safety) and cost (efficiency) [7]. Moreover, the European Society for Medical Oncology (ESMO) has undertaken the development of a validated and reproducible tool to assess the magnitude of the clinical benefits of anti-cancer interventions, the ESMO Magnitude of Clinical Benefit Scale (ESMO-MCBS) [8]. There is a growing need to define and adopt explicit decision criteria in the choice of new cancer drugs, and there is an agreement on the need to consider the opinions and preferences of the society. Although the definition and adoption of explicit decision criteria in the choice of new cancer drugs is a major breakthrough, it is important to note that the assessment of the value of any cancer treatment (efficacy, safety, quality of life, cost) may be different depending on healthcare systems and stakeholders. Therefore, decisions related to resource allocation should reflect the opinion and preferences of the society. Including citizen input in government priority-setting approaches is becoming more relevant and there is growing demand for 
governments to make resource allocation decisions in line with social values. Some studies have reported that in general, citizens and payers priorities for funding a new cancer drugs are different. Payers prioritize efficiency defined as health gains per dollar, while general population or patients prioritize equity understood as equal access to medicines independent of cost or effectiveness [9].

Understanding the value of a new cancer drug from different perspectives, including those of the general population and patients, can provide insight regarding the factors that should determine the value of new oncologic treatments. The objective of this work was to conduct an exploratory and qualitative study to investigate the main factors that drive innovation in oncology, and to determine the importance of each attribute from different perspectives: healthcare policy makers, oncologists, patients and the general population in Spain.

\section{METHODS}

\section{Study Participants}

Oncologists, healthcare policy makers, patients and the general population were invited to participate in the study. Oncologists working in the Spanish National Health System and with more than 10 years of professional experience; and healthcare policy makers with at least one political legislative period of experience at local regional or national level were selected to participate in the study. In order to assure that all participants were able to understand the questionnaire and willing to participate in the study, a convenience sample of the general population was used. This sample included employees of technology companies, research institutes, universities and governmental institutions. Finally, patients were contacted through local cancer associations and the Spanish Cancer Federation. New participants were contacted until saturation of information was reached [10].

Confidentiality was assured to all the participants in the study, and no incentives were offered for completing the questionnaire. All procedures followed were in accordance with the ethical standards of the responsible committee on human experimentation (institutional and national) and with the Helsinki Declaration of 1964, as revised in 2013. Given the study's nature, it did not require approval by an Ethics Committee.

\section{Structured Interview}

The structured interview was carried out by two interviewers between December 2013 and February 2014. Interviewers were trained and followed an interview guide which provided a clear set of instructions for interviewers in order to provide reliable, comparable qualitative data. The interview guide included three sections. Section 1 explored the importance of attributes on treatment choice, when comparing a new cancer drug with a standard cancer treatment. The responses were based on a 5-point Likert scale ("Not important" to "Very Important"). Section 2 included 16 statements related to the importance of survival, quality of life (QoL), costs and innovation in cancer treatment. Participants responded based on a 5-point Likert scale (1 "I absolutely disagree", 2 "I disagree", 3 "I am undecided", 4 "I agree", 5 "I absolutely agree"). Section 3 brought out the most worrying side effects related to cancer drugs. In this section, participants selected the three most worrying side effects from a list of the most common side effects related to cancer drugs, including nausea, dizziness, vomiting, 
pain, fatigue, hair loss, diarrhea, infection and rash [11, 12]. During the interview, general information about the respondents was also collected.

Results from two hypothetical decision-making scenarios (a life-prolonging scenario and a QoL-enhancing scenario) included in the study are published elsewhere [13].

\section{Data Analysis}

A descriptive analysis was conducted using SPSS v.19 (IBM Corp, Armonk, NY, USA). The percentage of each response based on a 5-point Likert scale in sections 1 and 2 was estimated. For section 3, the percentage of patients that selected each side effect was calculated.

\section{RESULTS}

\section{Participant Characteristics}

The qualitative convenience sample included a total of 188 individuals: 53 oncologists, 25 healthcare policy makers, 60 patients and 50 individuals from the general population [13].

\section{Importance of the Attributes of New Cancer Drugs on Treatment Choice}

These results are shown in Table 1.

For the total sample, when choosing treatments, the characteristics most highly rated by participants were greater efficacy (defined as increases in survival), greater safety (described as fewer or less severe side effects), improvements in QoL, adaptation of treatment to patients' individual requirements, and patients' rapid reincorporation to their daily activities. In almost all study groups, the percentages of "important" or "very important" responses were above $80.0 \%$. It is important to note that for the four study groups, greater efficacy was the highest rated treatment characteristic.

On the other hand, treatment features such oral rather than intravenous administration, potential direct cost savings (reduction of inpatient admissions) and potential indirect cost savings (improvement in work productivity) were less rated $(<80 \%$ of patients considered these characteristics "important" or "very important"). Compared to other study participants, more healthcare policy makers considered the attributes "treatment characteristics related to direct cost saving" and "lower cost" as being "important" or "very important" (88\% and 72\%, respectively).

\section{Perceived Innovation of New Cancer Drugs}

In order to assess perceived innovation of new cancer drugs, participants responded to 14 statements based on a 5-point Likert scale. The results showed that gains in survival and in QoL were key features of innovative oncology treatments. Table 2 shows the responses obtained in the 14 statements that evaluate the importance of the improvement in survival, safety, QoL and cost gained with new cancer drugs, and their contribution to innovation for the four study groups.

Regarding the questions related to survival, the healthcare policy makers group scored lowest. Therefore, compared to the rest of participants, healthcare policy makers considered that an additional improvement of 1-month survival associated to a new cancer drug (when the standard treatment provides 3 months' survival) would not be relevant. Similarly, a lower proportion of healthcare policy makers considered that when selecting treatment, the most important attribute was that the cancer drug provided additional 
Table 1 Importance of different attributes on treatment choice

\begin{tabular}{|c|c|c|c|c|}
\hline \multirow[t]{2}{*}{ Attribute of a new cancer drug } & \multicolumn{4}{|c|}{ \% of participants that consider the attribute "important" or "very important" } \\
\hline & $\begin{array}{l}\text { Oncologist } \\
(n=53)\end{array}$ & $\begin{array}{l}\text { Healthcare policy } \\
\text { maker }(n=25)\end{array}$ & $\begin{array}{l}\text { Patients } \\
(n=60)\end{array}$ & $\begin{array}{l}\text { General population } \\
(n=50)\end{array}$ \\
\hline Greater efficacy (increased survival) & 100.0 & 100.0 & 100.0 & 98.0 \\
\hline $\begin{array}{l}\text { Greater safety (fewer or less severe side } \\
\text { effects) }\end{array}$ & 100.0 & 96.0 & 90.0 & 98.0 \\
\hline $\begin{array}{l}\text { Improvement in health-related quality } \\
\text { of life }\end{array}$ & 98.1 & 84.0 & 100.0 & 96.0 \\
\hline $\begin{array}{l}\text { Treatment adaptation to patients' } \\
\text { clinical requirements }\end{array}$ & 100.0 & 80.0 & 96.7 & 88.0 \\
\hline $\begin{array}{l}\text { Rapid reincorporation of patients to } \\
\text { their daily activities }\end{array}$ & 96.2 & 80.0 & 78.3 & 90.0 \\
\hline $\begin{array}{l}\text { Oral rather than intravenous } \\
\text { administration }\end{array}$ & $60.4^{\mathrm{a}}$ & 56.0 & $60.0^{\mathrm{a}}$ & 66.0 \\
\hline $\begin{array}{l}\text { Direct cost savings (reduction of } \\
\text { hospital admissions) }\end{array}$ & 77.4 & 88.0 & 73.3 & 66.0 \\
\hline Lower cost & 56.6 & 72.0 & 50.0 & 44.0 \\
\hline $\begin{array}{l}\text { Indirect cost savings (work productivity } \\
\text { improvement) }\end{array}$ & 58.5 & 52.0 & 53.3 & 58.0 \\
\hline
\end{tabular}

a Differences related to the proportion of participants that considered the attribute "slightly important" or "not important" were detected: oncologists 3.77\%; healthcare policy makers $6.0 \%$, patients $15.7 \%$ and general population $8.0 \%$

survival despite increasing the risk of side effects.

Related to QoL, most patients and general population subjects agreed strongly or somewhat as to the importance of achieving gains in QoL, despite the new treatment not lengthening survival; while half of the healthcare policy makers and oncologists were of a similar opinion.

Most study participants agreed that patients should receive information regarding the budgetary impact of cancer treatment, even though they do not have to pay for it. Although most study participants agreed strongly or somewhat that the cost of a new treatment influences their approval and/or their choice of clinical practice, only half of patients agreed with this statement. Moreover, only a small proportion of the patients and the general population subjects considered that, when prescribing a cancer treatment, the oncologists should take economic aspects into account when choosing a particular treatment. Despite the fact that almost all study participants considered that every patient should have access to effective cancer treatments regardless of cost, only half of the healthcare policy makers agreed strongly or somewhat with this.

\section{Importance of Side Effects Related to Cancer Drugs}

The most worrying side effects were serious infections due to the compromised immune system imposed by oncology treatments, pain 
Table 2 Opinion on statements related to survival, health-related quality of life, cost and innovation

Statement

\begin{tabular}{llll} 
\% of participants stating "I agree” or "I absolutely agree" \\
\hline $\begin{array}{l}\text { Oncologist } \\
(n=53)\end{array}$ & Healthcare & Patients & General \\
& policy maker & $(n=60)$ & population \\
$(n=25)$ & & $(n=50)$
\end{tabular}

Survival

If the standard treatment for cancer provides 3 months'

54.7

28.0

58.3

62.0

survival, a drug that extends life 1 more month is relevant

At the time of treatment choice, the most important

39.6

16.0

50.0

44.0

attribute is that it provides additional survival, although it increases the risk of side effects

Health-related quality of life

During treatment choice, the most important attribute is that it improves the health-related quality of life, although it does not provide additional survival

\section{Cost}

It is important that patients should know the economic impact of treatments, even though they do not have to pay for them

The costs of new cancer drugs influence treatment choice and/or approval

Every patient should have access to effective cancer treatments regardless of their costs

The oncologists should consider the economic aspects when choosing a particular treatment

In the next 5 years, the costs of new cancer drugs will play a significant role in treatment recommendations

Innovation

New cancer drugs developed in the past decade have yielded significant innovations

Innovation provided by a new cancer drug is due to its improvement on quality of life

Innovation provided by a new cancer drug is due to its improvement on survival

Innovation provided by a new cancer drug is due to its improvement on safety

Innovation provided by a new cancer drug is due to its improvement on convenience of administration
56.6

44.0

72.0

79.2

88.0

78.3

84.0

84.9

96.2

56.0

98.3

100.0

71.7

100.0

10.0

34.0

88.7

100.0

56.0

96.2

88.3

92.0

86.0

90.6

80.0

90.0

98.1

84.0

96.7

96.0

81.2

76.0

88.3

74.0

77.4

72.0

70.0

56.0 
Table 2 continued

\begin{tabular}{|c|c|c|c|c|}
\hline \multirow[t]{2}{*}{ Statement } & \multicolumn{4}{|c|}{$\%$ of participants stating "I agree" or "I absolutely agree" } \\
\hline & $\begin{array}{l}\text { Oncologist } \\
(n=53)\end{array}$ & $\begin{array}{l}\text { Healthcare } \\
\text { policy maker } \\
(n=25)\end{array}$ & $\begin{array}{l}\text { Patients } \\
(n=60)\end{array}$ & $\begin{array}{l}\text { General } \\
\text { population } \\
(n=50)\end{array}$ \\
\hline $\begin{array}{l}\text { Innovation provided by a new cancer drug is due to the } \\
\text { development of strategies aimed at a specific target }\end{array}$ & 100.0 & 80.0 & 93.3 & 78.0 \\
\hline
\end{tabular}

and vomiting. Hair loss had a greater relevance for healthcare policy makers (40.0\%) and patients (31.7\%) compared to oncologists (15.1\%) or the general population participants (20.0\%) (Table 3).

\section{DISCUSSION}

In cancer care, value is often understood as treatment benefits or quality-of-care weighed against economic cost. Some approaches have been developed in order to define the value of new cancer drugs. The conceptual framework proposed by ASCO is based on clinical benefits (efficacy), toxicity (safety) and cost [8], while ESMO-MCBS is mainly based on the magnitude of clinical benefit, QoL and toxicity [9]. Despite these approaches, value considerations may differ among stakeholders. The results of this study, that aimed to explore the main factors that drive innovation in oncology from different perspectives, revealed that gains in QoL, survival, safety, cost and innovation are perceived differently by different groups of stakeholders. For example, although improvements in QoL are considered an important added value for new cancer drugs by all the respondents, there were differences among participants regarding the value assigned to QoL when compared to survival.

Differences were also observed related to economic factors and safety. Healthcare policy makers gave greater importance to the economic impact related to oncology treatment costs than other participants. Compared with other participants, a higher proportion of patients agreed to select a treatment that provides additional survival despite increasing the risk of side effects.

Similar results are described in other studies. In the United States, study findings revealed that oncologists value length of survival highly compared to improvements in QoL when taking chemotherapy decisions [14]. A study conducted in Israel identified differences in the perception of the value of cancer health among family physicians and oncologists [15]. Family physicians valued life-prolonging and QoL-enhancing interventions roughly equally, while oncologists valued interventions that extended survival highly compared with those that improved only QoL. It has been suggested that these findings may have important implications in the coverage and reimbursement decisions of new cancer treatments $[14,16]$. Although achieving gains in survival was considered highly important among all participants, healthcare policy makers demanded a greater survival improvement, compared to the other respondents, in order to justify the added value of an innovative cancer treatment.

With regard to cancer drug cost, some studies had reported that cancer patients are largely desensitized to the cost of their treatment, mainly because of their insurance 
Table 3 Importance of the side effects for the 4 groups of participants (in bold the three adverse events with higher values)

\begin{tabular}{|c|c|c|c|c|}
\hline \multirow[t]{2}{*}{ Side effects } & \multicolumn{4}{|c|}{$n$ (\% participants) } \\
\hline & $\begin{array}{l}\text { Oncologist } \\
(n=53)\end{array}$ & $\begin{array}{l}\text { Healthcare policy } \\
\text { maker }(n=25)\end{array}$ & $\begin{array}{l}\text { Patients } \\
(n=60)\end{array}$ & $\begin{array}{l}\text { General population } \\
(n=50)\end{array}$ \\
\hline Nausea & $9(17.0)$ & $4(16.0)$ & $7(11.7)$ & $6(12.0)$ \\
\hline Vomiting & $29(54.7)$ & $7(28.0)$ & $20(33.3)$ & $16(32.0)$ \\
\hline Pain & $42(79.2)$ & $21(84.0)$ & $41(68.3)$ & $41(82.0)$ \\
\hline Fatigue & $11(20.8)$ & $2(18.0)$ & $15(25.0)$ & $10(20.0)$ \\
\hline Dizziness & $5(9.4)$ & $0(0)$ & $6(10.0)$ & $10(20.0)$ \\
\hline Hair loss & $8(15.1)$ & $10(40.0)$ & $19(31.7)$ & $10(20.0)$ \\
\hline Diarrhea & $7(13.2)$ & $3(12.0)$ & $9(15.0)$ & $8(16.0)$ \\
\hline $\begin{array}{l}\text { Serious infections due to } \\
\text { compromised immune system }\end{array}$ & $43(81.0)$ & $20(80.0)$ & $46(76.7)$ & $40(80.0)$ \\
\hline Rash & $1(1.9)$ & $6(24.0)$ & $10(16.7)$ & $9(18.0)$ \\
\hline Others & $1(1.9)$ & $2(8.0)$ & $7(11.7)$ & $0(0)$ \\
\hline
\end{tabular}

coverage, meaning that drug prices are not significantly constrained by patients' willingness to pay [17] and in some cases, the value of treatment exceeds the total amount paid by them and their insurer [18]. However, nowadays, mainly due to the economic sustainability of health system has become a cornerstone of global economic policies, this is changing. The rising cost of cancer drugs is creating unintended financial consequences for patients. Cancer patients must face potential financial stresses related to out-pocket expenditures (medical or non-medical expenses), loss of earnings (patient and relatives), being increasingly more concerned about cancer drug cost $[19,20]$.

In line with our results that showed that all participants agree that patients should receive information regarding the budgetary impact of cancer treatment, even though they do not have to pay for it, some studies conclude that many clinicians consider that cost information should be shared with patients rather than making clinical recommendations based on cost without patients' input [21].

A review that aims to identify and compare the preferences of patients, the general public and payers to determine the values that should shape public funding decisions for new cancer drugs, suggests that payers consider many factors and prioritize efficiency in funding decisions, while patients and the general public consider fewer factors and prioritize access to cancer treatments with the potential to save or extend life [9].

Finally, as per the safety of new cancer drugs, a recent study that aimed to investigate the attitudes of physicians, healthy control subjects and melanoma patients towards a specific drug showed that patients strived for a longer life regardless of the side effects and tumor response rates, whereas physicians were reluctant to use therapies with a higher incidence of side effects and marginal cancer response benefits [22].

These findings need to be understood in the context of sample biases and ambit of the study. 
A convenience sample of general population was used, not being representative of the general population. Even though the sample size of the study is not very large, there is a vast range of sample sizes used in qualitative studies, with the most common sample size being between 20 and 30 interviews [10]. Further research is needed to establish the magnitude of meaningful differences in the views of cancer treatment innovation in the Spanish Health System.

This study describes an overall view of the similarities and differences in the gains in drug safety, QoL, survival, compliance with patients' clinical characteristics and costs as a means of evaluating the perception of the added value of a new cancer treatment by different stakeholders in Spain. The differences observed in the study highlight the need to consider the perspective of different stakeholders in the assessment of a new cancer drugs to obtain more informed decisions when deciding on the most appropriate treatment to use, and contribute to the debate on the definition of the value of innovation in oncology addressing the different perspectives.

\section{CONCLUSION}

In conclusion, since QoL, survival, safety, cost and innovation are perceived differently by stakeholders, this should be considered during the assessment of a new cancer drug.

\section{ACKNOWLEDGMENTS}

The authors are extremely grateful to all study participants who contributed with their time to participate in this research. Sponsorship, publication charges, and the open access charge for this study were funded by Eli Lilly
\& Co, Madrid (Spain). All named authors meet the International Committee of Medical Journal Editors criteria for authorship for this manuscript, take responsibility for the integrity of the work as a whole, and have given final approval to the version to be published.

Disclosures. José A. Sacristán is an employee of Eli Lilly \& Co. Tatiana Dilla is an employee of Eli Lilly \& Co. Luís Lizan, Marta Comellas, Pilar Garrido, Cristina Avendaño, Juan J. Cruz-Hernández and Javier Espinosa have nothing to disclose.

Compliance with Ethics Guidelines. All procedures followed were in accordance with the ethical standards of the responsible committee on human experimentation (institutional and national) and with the Helsinki Declaration of 1964 , as revised in 2013. Given the study's nature, it did not require approval by an Ethics Committee.

Open Access. This article is distributed under the terms of the Creative Commons Attribution-NonCommercial 4.0 International License (http://creativecommons.org/licenses/ by-nc/4.0/), which permits any noncommercial use, distribution, and reproduction in any medium, provided you give appropriate credit to the original author(s) and the source, provide a link to the Creative Commons license, and indicate if changes were made.

\section{REFERENCES}

1. Ferlay J, Soerjomataram I, Dikshit R, Eser S, Mathers C, Rebelo M, et al. Cancer incidence and mortality worldwide: sources, methods and major patterns in GLOBOCAN 2012. Int J Cancer. 2015;136(5):E359-86. 
2. National Cancer Institute, Surveillance Epidemiology and End Results. Available at http:// publications.iarc.fr/Non-Series-Publications/WorldCancer-Reports/World-Cancer-Report-2014. Accessed Nov 2014.

3. Patel JD, Krilov L, Adams S, Aghajanian C, Basch E, Brose MS, et al. Clinical cancer advances 2013: annual report on progress against cancer from the American Society of Clinical Oncology. J Clin Oncol. 2014; 32(2):129-60. Available at http://jco. ascopubs.org/content/32/2/129.full.pdf+html. Accessed Nov 2014.

4. Hoverman JR, Cartwright TH, Patt DA. Pathways, outcomes, and costs in colon cancer: retrospective evaluations in two distinct databases. J Oncol Pract. 2011;7(3 Suppl):52s-9s.

5. Siddiqui M, Rajkumar SV. The high cost of cancer drugs and what we can do about it. Mayo Clin Proc. 2012;87(10):935-43. Available at http://www.ncbi. nlm.nih.gov/pmc/articles/PMC3538397/pdf/main. pdf. Accessed 4 March 2015.

6. Sorenson C, Drummond M, Kanavos P. Ensuring value for money in healthcare: the role of health technology assessment in the European Union. European observatory on health systems and polices. Observatory studies series No 11. Copenhagen: WHO; 2008. Available at http:// www.euro.who.int/_data/assets/pdf_file/0011/982 91/E91271.pdf. Accessed 15 Dec 2015.

7. Schnipper LE, Davidson NE, Wollins DS, Tyne C, Blayney DW, Blum D, et al. American Society of Clinical Oncology Statement: a conceptual framework to assess the value of cancer treatment options. J Clin Oncol. 2015;33(23):2563-77.

8. Cherny NI, Sullivan R, Dafni U, Kerst JM, Sobrero A, Zielinski C, et al. A standardised, generic, validated approach to stratify the magnitude of clinical benefit that can be anticipated from anti-cancer therapies: the European Society for Medical Oncology Magnitude of Clinical Benefit Scale (ESMO-MCBS). Ann Oncol. 2015;26(8):1547-73.

9. MacLeod TE, Harris AH, Mahal A. Stated and revealed preferences for funding new high-cost cancer drugs: a critical review of the evidence from patients, the public and payers. Patient. 2016;9(3):201-22. doi:10.1007/s40271-015-0139-7.

10. Marshall B, Cardon P, Poddar A, Fontenot R. Does sample size matter in qualitative research? A review of qualitative interviews in is research. J Comput Inform Syst. 2013;54(1):11-22.

11. Mao JJ, Chung A, Benton A, Hill S, Ungar L, Leonard CE, Hennessy S, Holmes JH. Online discussion of drug side effects and discontinuation among breast cancer survivors. Pharmacoepidemiol Drug Saf. 2013;22(3):256-62.

12. National Cancer Institute. Available at http://www. cancer.gov/about-cancer/treatment/side-effects. Accessed Sept 2014.

13. Dilla T, Lizan L, Paz S, Garrido P, Avendaño C, Cruz-Hernández JJ, Espinosa J, Sacristán JA. Do new cancer drugs offer good value for money? The perspectives of oncologists, health care policy makers, patients, and the general population. Patient Prefer Adher. 2015;18(10):1-7.

14. Kozminski MA, Neumann PJ, Nadler ES, Jankovic A, Ubel PA. How long and how well: oncologists' attitudes toward the relative value of life-prolonging v. quality of life-enhancing treatments. Med Decis Making. 2011;31(3):380-5.

15. Greenberg D, Hammerman A, Vinker S, Shani A, Yermiahu $\mathrm{Y}$, et al. Which is more valuable, longer survival or better quality of life? Israeli oncologists' and family physicians' attitudes toward the relative value of new cancer and congestive heart failure interventions. Value Health. 2013;16(5):842-7.

16. Greenberg D, Hammerman A, Vinker S, Shani A, Yermiahu Y, Neumann PJ. Oncologists' and family physicians' views on value for money of cancer and congestive heart failure care. Isr J Health Policy Res. 2013;2:44. doi:10.1186/2045-4015-2-44.

17. Schickedanz A. Of value: a discussion of cost, communication, and evidence to improve cancer care. Oncologist. 2010;15(Suppl 1):73-9.

18. Goldman DP, Jena AB, Lakdawalla DN, Malin JL, Malkin JD, Sun E. The value of specialty oncology drugs. Health Serv Res. 2010;45(1):115-32.

19. Zafar SY, Abernethy AP. Financial toxicity, part I: a new name for a growing problem. Oncology (Williston Park). 2013;27(2):80-149.

20. Zafar SY, Peppercorn JM, Schrag D, Taylor DH, Goetzinger AM, Zhong X, Abernethy AP. The financial toxicity of cancer treatment: a pilot study assessing out-of-pocket expenses and the insured cancer patient's experience. Oncologist. 2013;18(4):381-90.

21. Herikson N, Tuzzio L, Loggers ET, Miyoshi J, Buist D. Patient and oncologist discussions about cancer care costs. Support Care Cancer. 2014;22(4):961-7.

22. Krammer R, Heinzerling L. Therapy preferences in melanoma treatment-willingness to pay and preference of quality versus length of life of patients, physicians and healthy controls. Plos One. 2014;9(11):e111237. 